\title{
Os sentidos e disputas na construção da Política Nacional de Promoção da Saúde
}

\section{| ${ }^{1}$ Patrícia Ferrás Araújo da Silva, 2 Tatiana Wargas de Faria Baptista |}

Resumo: Este estudo teve como objetivo analisar a definição da Política Nacional de Promoção da Saúde de 2006 no Brasil, buscando explicitar os sentidos e disputas no processo de formulação e suas implicações para o campo da saúde. Para tanto, foram feitas revisão bibliográfica, análise de documentos e entrevistas com participantes da rede de discussão sobre promoção da saúde no Brasil. Partimos de uma visão de ciência construcionista, compreendendo a política como um processo dinâmico que se constitui a partir de diferentes fatores que influenciam as escolhas e posicionamentos dos atores e grupos. Identificamos no processo alguns tensionamentos que podem ser entendidos como dilemas que o debate da promoção suscita. Um primeiro dilema apresentou-se no debate propriamente dito em torno do modelo de promoção, que decorre da polarização historicamente construída entre a perspectiva regulatória e a perspectiva emancipatória. Um segundo dilema refere-se à apropriação desta polarização se desdobrando na discussão entre o amplo e o restrito, onde as propostas voltadas para o coletivo são tidas como comprometidas com um projeto emancipatório e as propostas voltadas para o individual são entendidas numa perspectiva de controle. $\mathrm{O}$ terceiro dilema se traduziu no emprego do conceito de empowerment sem uma discussão aprofundada de seus efeitos no processo de construção desta política em nosso âmbito.

> Palavras-chave: promoção da saúde; política de saúde; formulação de políticas.

\author{
1 Secretaria de Gestão do \\ Trabalho e Educação na Saúde \\ (SGTES), Departamento de \\ Gestão e da Regulação do \\ Trabalho em Saúde (DEGERTS). \\ Rio de Janeiro, Brasil. Endereço \\ eletrônico: patriciaferras@ \\ hotmail.com \\ 2 Escola Nacional de Saúde \\ Pública Sergio Arouca (ENSP). \\ Rio de Janeiro, Brasil. Endereço \\ eletrônico: twargas@ensp. \\ fiocruz.br
}




\section{Introdução}

A "promoção da saúde" tem sido bastante discutida e divulgada em fóruns e debates da saúde, nacional e internacional, aparecendo em alguns dos principais documentos oficiais do campo como estratégia e/ou prioridade para alcançar melhores condiçõoes de saúde da população. Contudo, é perceptível a diferença de ênfases e entendimentos de promoção presentes nos debates, documentos institucionais e práticas em serviço. Alguns sentidos são facilmente identificáveis como a ideia de promoção associada à realização de ações de educação sanitária e grupos de orientação terapêutica, com o foco estrito na prevenção e controle das doenças e ênfase nos estilos de vida e hábitos saudáveis. Outro sentido é aquele que remete a discussões mais abrangentes sobre os determinantes da saúde e doença, fazendo a associação entre promoção, autonomia e emancipação de sujeitos no cuidado, através de políticas de natureza intersetorial. Tais variações refletem, de algum modo, os sentidos de promoção que perpassam o debate sobre saúde na atualidade e remetem a diferentes usos deste termo no campo da saúde pública desde seus primórdios.

A definição da Política Nacional de Promoção da Saúde no Brasil (PNPS), instituída em 2006 (BRASIL, 2006), nos instigou a buscar compreender de que concepção de promoção está se falando no contexto desta política e se sua definição pode ou não contribuir para a construção de uma prática em saúde emancipatória e não restrita ao ambiente de saúde. Identificamos no campo tensionamentos entre grupos e diferentes apostas e visōes da promoção, que tanto podem ser vistos como uma proposta de organização que visa ampliar o debate e entendimento de saúde, trazendo novos atores e setores para discussão, como pode ser vista como uma estratégia política que visa reduzir a atuação do Estado e responsabilizar os indivíduos pela sua saúde.

A Promoção da Saúde surge e ganha força enquanto "movimento" no cenário internacional a partir da década de 1970, no Canadá, onde ocorrem os primeiros eventos que resultaram nos principais documentos oficiais sobre o tema. No pós-guerra, com o avanço do capitalismo, os países desenvolvidos estabeleceram modelos de proteção social que ampliavam e garantiam o acesso da população a serviços sociais, que configuravam as bases dos direitos de cidadania. Durante os chamados "trinta anos gloriosos" consolidaram-se o direito à saúde e o aumento 
dos gastos na assistência. Após este período, o cenário de esgotamento de recursos do contexto político-econômico da década de 1970 configurou a crise dos Estados de Bem-Estar Social (EBES), fazendo com que as políticas sociais e, em específico, as políticas de saúde, passassem a ser alvo de crítica e reflexão, tendo em vista os altos e crescentes custos da assistência médica. Tudo isso mobilizou o Estado em busca de alternativas para o enfrentamento da questão.

A primeira iniciativa foi em 1974, quando Marc Lalonde, então ministro da Saúde do Canadá, publicou o primeiro documento oficial a receber a denominação de Promoção da Saúde, conhecido como "Informe Lalonde", que inter-relacionava quatro grupos explicativos do fenômeno saúde/doença: ambiente, estilo de vida, biologia humana e organização dos serviços de saúde (FERREIRA et al., 2011).

O documento trouxe inovações para o campo da saúde, voltando e ampliando o debate para os determinantes sociais da saúde em detrimento da centralidade do modelo curativo, centrado na figura do médico, que já mostrava sinais de insuficiência para responder de maneira satisfatória aos problemas de saúde mais gerais. Ao mesmo tempo, disparou um forte conteúdo regulatório da vida cotidiana, preventivista, individualizando as questões acerca do processo saúde-doença, na medida em que colocava o estilo de vida em foco no debate, negligenciando o contexto político, econômico e social. A partir de então, a temática ganhou destaque e foi tema de encontros e documentos subsequentes, com expressão mundial, influenciando diversos países. No entanto, não se fazia uma crítica ao modelo de Estado e à organização do sistema mundial, ou ao que gerava desigualdade ou doença, por isso o modelo constituiu-se mais regulatório em detrimento da ideia de produção de saúde ou de um pensamento mais emancipatório.

Os anos 1980 se iniciam com o debate em curso acerca da Promoção da Saúde. Pode-se dizer que o principal evento da década e marco para a mudança do paradigma do Movimento de Promoção da Saúde foi a I Conferência Internacional sobre Promoção da Saúde, em Ottawa, Canadá, em novembro de 1986. O relatório final se constituiu como um dos documentos fundadores da "Nova Promoção da Saúde", propondo um "novo olhar" sob a ótica dos determinantes e condicionantes da saúde. Tal olhar constituiu um avanço no debate proposto, na medida em que passava a entender que para promover saúde era necessário ir além de propor a alteração do estilo de vida, já que este se 
reportava exclusivamente à esfera individual, devendo-se trabalhar na perspectiva do conceito ampliado de saúde. A partir de então, há maior divulgação e oferta do movimento enquanto estratégia de política pública para os países redesenharem seus modelos de assistência à saúde, com diversas conferências que reafirmavam os conceitos e produziam documentos norteadores.

No Brasil, o debate da promoção tal qual vinha sendo disseminado nas primeiras investidas internacionais ainda não tinha entrada, ao menos não nomeado desta forma. Nos anos 1970, o debate brasileiro concentrava-se na crítica ao modelo de saúde vigente e às condições sociais produtoras de doença. Em meio ao regime autoritário, as discussões eram permeadas pela forte repressão política e ideológica que, apesar de dificultarem a expressão da crítica, não puderam evitar o espraiamento do início dos movimentos sociais que viriam a influenciar o processo de redemocratização.

Dentre as críticas ao sistema de saúde, destacou-se a tese do sanitarista Sérgio Arouca, apresentada em 1976, intitulada $O$ dilema preventivista. O trabalho denunciava o alcance do modelo da medicina preventiva indicando seu caráter de manutenção de determinado projeto político de Estado excludente e desigual. $\mathrm{O}$ processo explicativo da medicina preventiva representava uma simplificação do real e um afastamento das determinações, focalizando apenas uma dimensão no cuidado à saúde em detrimento da discussão da causa das causas (AROUCA, 2003).

Assim o debate brasileiro avançava em meio ao processo de redemocratização e teve como grande marco a $8^{\text {a }}$ Conferência Nacional da Saúde (CNS), com a participação da população nas discussões. O Relatório Final da Conferência definiu a saúde em seu sentido abrangente, como resultante das condições de alimentação, habitação, educação, renda, meio-ambiente, trabalho, transporte, emprego, lazer, liberdade, acesso e posse da terra e acesso a serviços de saúde. Subsidiou tanto o texto da Constituição Federal de 1988 como das leis orgânicas da saúde, nos 8.080/90 e 8.142/90, afirmando o conceito ampliado de saúde, que levava em consideração outras necessidades básicas, um ambiente propício para crescimento e desenvolvimento e a busca da realização plena do potencial humano (CARVALHO, 2008). Tal definição indicava a necessidade de constituir uma ação institucional que envolvesse promoção, proteção e recuperação da saúde e não apenas ações restritas ao processo mais imediato de cuidado da doença. 
Somente no final dos anos 1990 é que a Promoção da Saúde se afirmou no contexto nacional e ganhou alguma institucionalidade no Ministério da Saúde, com a formalização da cooperação com o Programa das Nações Unidas para o Desenvolvimento - PNUD (BUSS, 2009).

A primeira iniciativa na esfera federal de proposta oficial de política de Promoção da Saúde foi feita em 2002, quando o Ministério da Saúde elaborou o documento intitulado "Política Nacional de Promoção da Saúde (Documento para discussão)" (BRASIL, 2002). Entretanto, a PNPS só foi formalizada em 2006, como consequência da formulação do Comitê Gestor da Política Nacional de Promoção da Saúde (CGPNPS), instituído em 2005, composto por representantes dos diversos segmentos do Ministério da Saúde, porém sem a participação das outras esferas de governo ou da sociedade civil. Dentre suas atribuiçōes, além de propor a política, o comitê deveria consolidar a "Agenda Nacional de Promoção da Saúde 2005-2007” (BUSS, 2009). Desta forma, os anos 2000 concretizam a entrada da Promoção da Saúde na agenda governamental brasileira, com a presença da temática nas principais legislaçōes de saúde.

\section{Métodos}

$\mathrm{Na}$ construção de caminhos para análise da PNPS fizemos algumas escolhas, percebendo e assumindo uma visão de política como um processo dinâmico, que não é algo dado, que não se constitui a partir de causas e efeitos, mas de diferentes fatores que influenciam as escolhas e posicionamentos dos atores e grupos, de disputas entre interesses; como algo que se "constitui" a partir de embates que mudam, que se transformam, com atores implicados. Desta forma, passamos a adotar como perspectiva que "não é suficiente tratar os processos políticos apenas no que é aparente ou formalmente estabelecido; é preciso romper com uma visão normativa e descritiva das políticas e trazer o que há de vida na sua construção" (BAPTISTA; MATTOS, 2011, p. 13). Para tanto, partimos de uma visão de ciência construcionista (MATTOS, 2011), ou seja, a ciência entendida como a construção de uma narrativa, onde não existe uma realidade a ser desvendada.

$\mathrm{Na}$ realização do estudo, utilizamos três estratégias metodológicas que, combinadas, nos permitiram reunir elementos para a construção da análise sobre a política, quais sejam: revisão bibliográfica do tema no debate nacional e sua interface com o debate internacional, análise de documentos nacionais e a 
realização de entrevistas com participantes da rede de discussão sobre promoção da saúde no Brasil. Na revisão bibliográfica, fizemos o levantamento dos principais autores que discutem a promoção da saúde, desde os primeiros usos do termo no campo da saúde pública. E na análise de documentos, buscamos os documentos oficiais específicos de promoção e demais documentos do Ministério da Saúde que dialogam com a PNPS de 2006, assim como documentos gerados em seminários, oficinas da Associação Brasileira de Pós-Graduação em Saúde Coletiva (Abrasco) e Conferências nacionais e internacionais sobre Promoção da Saúde.

No conjunto de documentos analisados, destaca-se aquele apresentado em 2002 pelo Ministério da Saúde para discutir a Política Nacional de Promoção da Saúde. A análise do documento suscitou uma série de reflexões sobre o processo de construção da política de 2006 e reuniu argumentos importantes para a análise de seu processo de formulação, em especial para a compreensão das diferentes posições e compreensões em torno do conceito de promoção no debate dentro do campo e no contexto da reforma sanitária. A análise de documentos esteve pautada tanto por uma leitura temática como pela identificação dos argumentos apresentados inseridos no contexto político e na rede de atores produtores de cada documento, tendo como referência a discussão proposta por Spink para produção de sentidos (SPINK, 2004).

As entrevistas foram realizadas a partir de um roteiro elaborado com questões que pudessem suscitar a reflexão dos atores a respeito do momento em que participaram da construção da política, tomando de empréstimo o referencial de Giddens da teoria da estruturação (GIDDENS, 2003). Identificamos os atores participantes do debate da promoção na fala dos entrevistados, um fazendo referência ao outro. Foram entrevistados seis atores da rede, sendo quatro advindos do Ministério da Saúde (Secretaria Executiva - SE e Secretaria de Vigilância em Saúde - SVS) e dois representantes das instituições acadêmicas. Vale ressaltar que apesar do número de entrevistados, percebemos a saturação das questões de pesquisa a cada entrevista, ou seja, as mesmas discussões foram apontadas pelos diferentes entrevistados, com pequenas diferenças de nuance e posição com relação ao tema, sugerindo que não seria necessário buscar outros atores para o entendimento do debate.

A pesquisa teve a aprovação do Comitê de Ética em Pesquisa (protocolo CEP/ ENSP n ${ }^{\circ}$ 127/11 CAAE: 0131.0.031.000.11) e cumpriu todos os requisitos para a boa prática e ética em pesquisa. 


\section{A Promoção da Saúde nos documentos de 2002 e 2006}

Apesar da ordem cronológica dos acontecimentos em torno da construção de um texto para a conformação da PNPS, não houve necessariamente uma continuidade em sua redação, pois ao analisarmos os documentos de 2002 e 2006, percebemos pontos de convergência/divergência, rupturas e contradições em torno do que se entende por Promoção da Saúde.

Há diferenças importantes de estratégia dos dois documentos. Enquanto no documento de 2002 propôs-se uma discussão abrangente sobre a promoção da saúde, o de 2006 definiu-se com o objetivo programático de estabelecer açôes claramente delimitadas. Tais diferenças explicitam-se no formato e argumentos apresentados em cada um dos textos. Talvez uma das maiores diferenças entre os dois documentos seja as referências bibliográficas utilizadas para respaldar as discussões e propostas. O documento de 2002 utiliza uma vasta bibliografia com autores que representam um processo reflexivo significativo, como Paulo Freire, Milton Santos, Boaventura Souza Santos, Leonardo Boff, Edgard Morin, Pierre Bourdieu, além de referências internacionais importantes sobre o campo. Já o documento de 2006 recorreu exclusivamente a textos nacionais oficiais, reduzindo sua capacidade de alcance em relação à complexidade do tema. Também é curioso que o documento de 2002 não conste como referência bibliográfica na PNPS de 2006.

O documento de 2002 parte do reconhecimento do movimento internacional da Promoção da Saúde, acatando, assim como os demais países participantes, suas recomendações em torno do pensar promoção de maneira mais específica, como prioridade para políticas e programas. Já a operacionalização da proposta é ampla, envolvendo açōes mais abrangentes na busca pela reorientação dos serviços e mudanças no modelo de atenção.

O documento de 2006 apresenta um panorama geral da promoção da saúde, localizando o debate como estratégia de articulação transversal, com estreita relação com a perspectiva da vigilância em saúde. A parte inicial do texto faz um esforço em conceituar a promoção da saúde a partir dos marcos legais das Cartas da Promoção, mas apresenta um foco restrito quando se propõe a operar na "redução dos riscos de adoecer". O documento apresenta também uma trajetória resumida do campo, com menção aos principais eventos para a entrada da Promoção no Brasil como a $8^{a}$ CNS. 
Para melhor compreender as diferenças entre os documentos, estabelecemos dispositivos de análise para aprofundarmos o debate, sem a pretensão de esgotálos (quadro 1). Trata-se de visualizar as transformaçōes ocorridas ao longo da produção do texto da política, não somente do ponto de vista de sua redação, mas dos sentidos em disputa que definiram as escolhas conceituais da perspectiva que prevaleceu na PNPS em 2006, como vemos a seguir.

No documento de 2002, a reforma sanitária é tratada como tema fundamental, ponto de partida para as reformas no setor saúde, e por este motivo uma PNPS deveria ser pensada com o compromisso de aprofundar as promessas da reforma, estando intimamente relacionadas. O conceito de autonomia é apresentado na perspectiva de Paulo Freire, num olhar para os indivíduos e comunidades, sendo relacionado ao conceito de produção de saúde. Com isso, reposiciona também o debate da participação comunitária, não a restringindo a controle social, colocando em discussão a possibilidade de participação da sociedade nos diferentes momentos de delimitação das ações públicas e de intervenção do Estado, desde a definição de prioridades até as decisões de gestão. Neste sentido, a participação não se associa à ideia de empoderamento, mas à discussão de complexidade. $\mathrm{O}$ termo empoderamento não é utilizado nesse documento.

Outro conceito importante iluminado no documento de 2002 é o de emancipação. Ressalta-se a necessidade de um processo amplo de emancipação da nação, fazendo referência ao conceito de Milton Santos, devendo-se discutir alternativas que busquem esse caminho. Este conceito apresenta-se ligado ao de intersetorialidade, na valorização de um olhar mais abrangente do Estado, com a preocupação em relação ao planejamento enquanto questão crucial para o SUS, que deve ser conjunto, deve contribuir para a superação da fragmentação do Estado moderno, enquanto Estado-nação, não se tratando exclusivamente do setor saúde.

Numa perspectiva mais delimitadora da ação política, o documento tece uma discussão ampla acerca do conceito de risco, relacionando-se ao mundo moderno, aos determinantes sociais, ao consumo pela escassez ou excesso, de forma mais abrangente, considerando também o risco social e pessoal. Mas não há no documento qualquer menção à vulnerabilidade. O documento da Política de 2002 não apresenta propostas ou ações específicas, mas ressalta a necessidade do estabelecimento de evidências que comprovem a efetividade das ações; ações estas que deveriam ser utilizadas para relacionar as condiçóes de vida ao processo saúde-doença, reconhecendo as especificidades de cada contexto. 


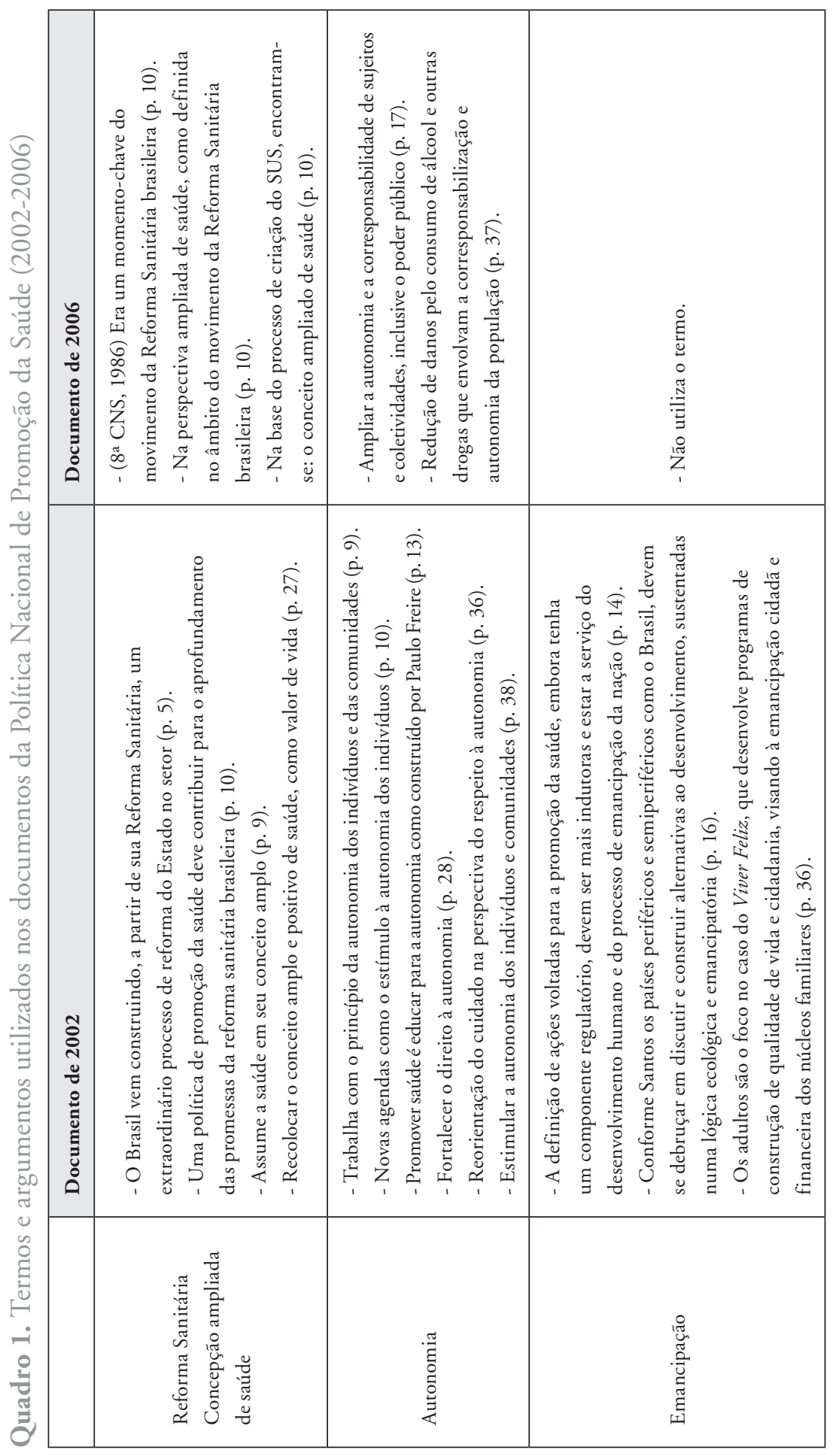




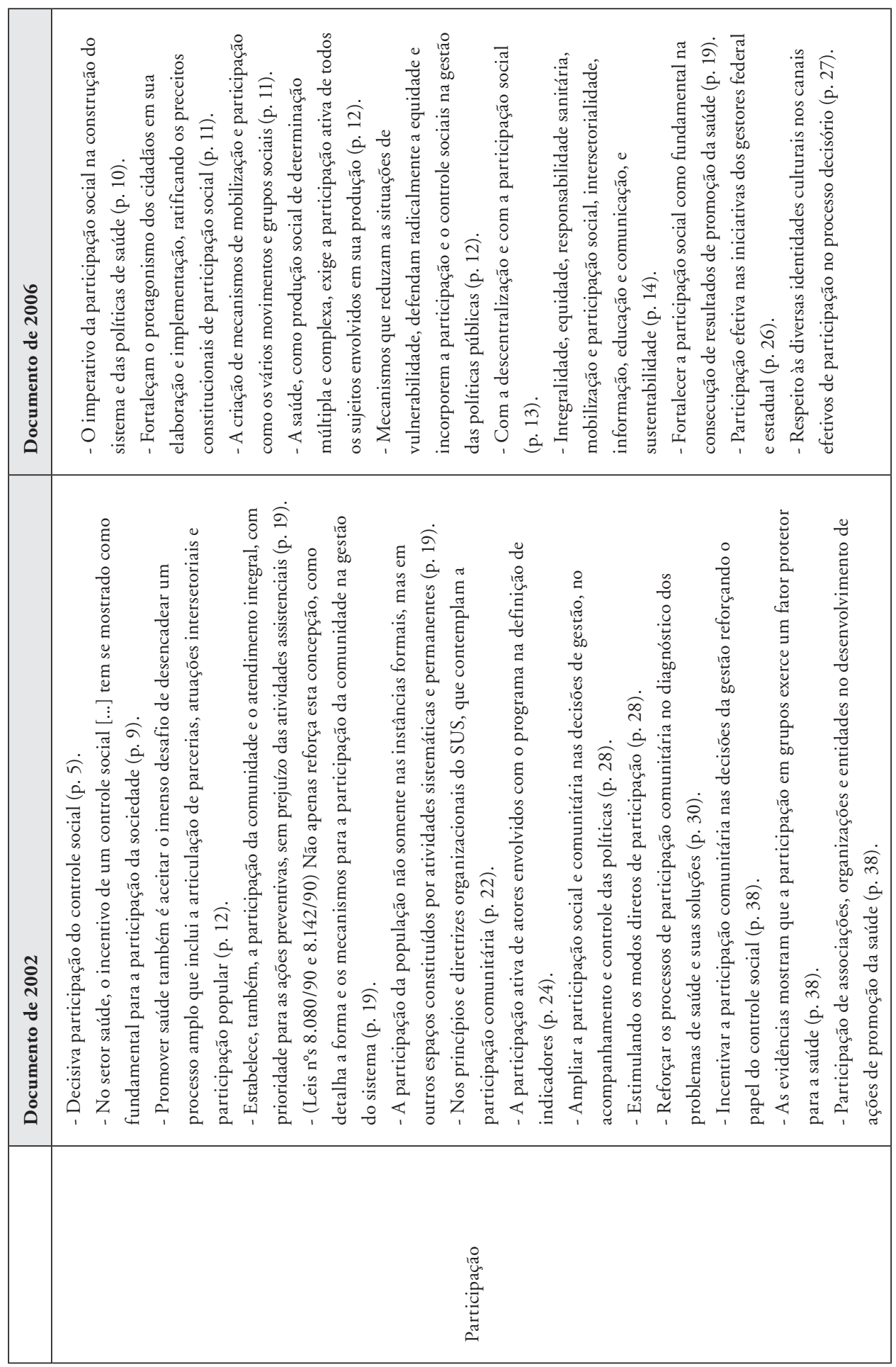




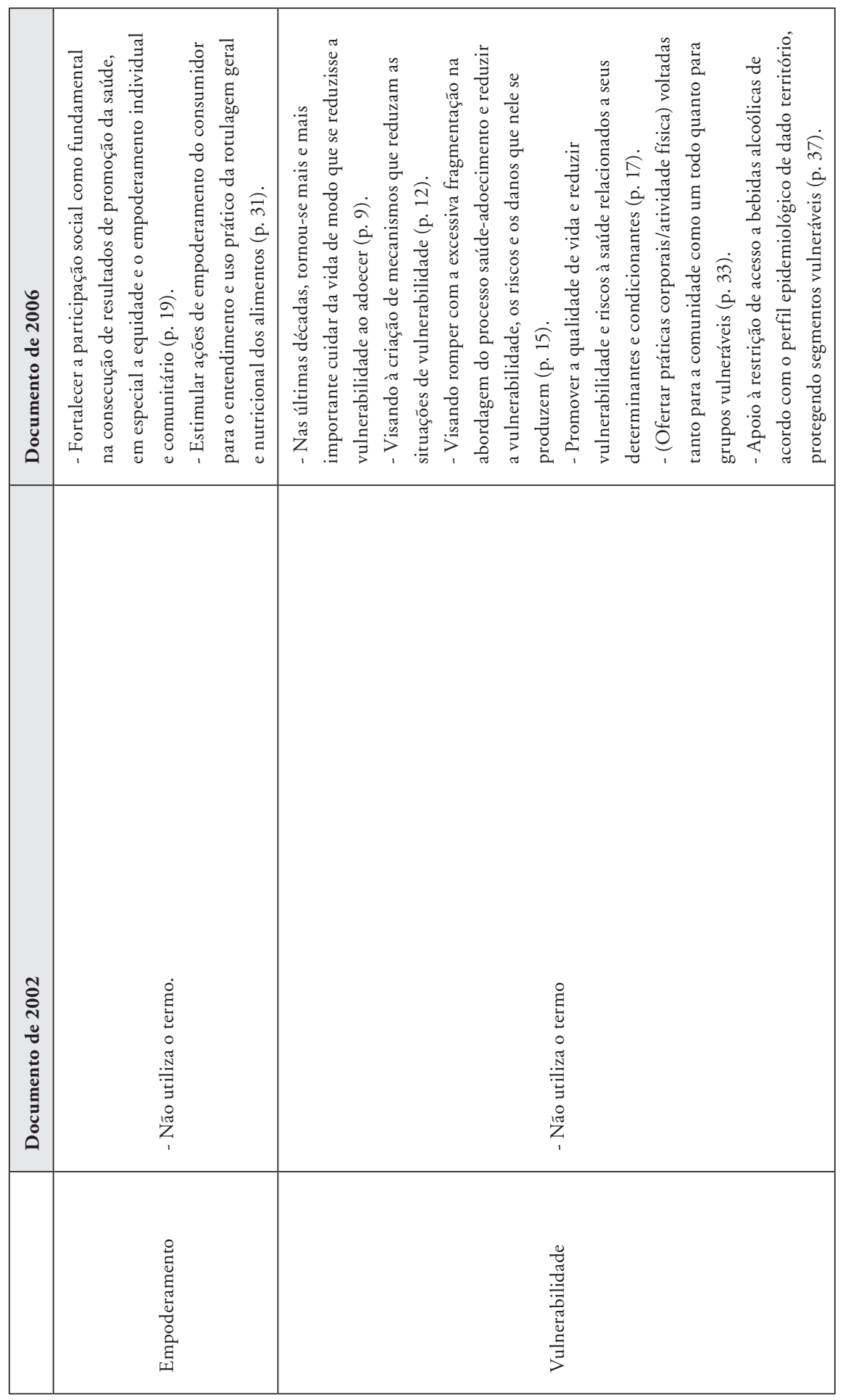


Já no documento de 2006, a reforma sanitária é tratada ao considerar o processo histórico, remetendo-se ao momento da $8^{\mathrm{a}} \mathrm{CNS}$ como crucial, mas não aprofunda o debate. Nesse documento, o conceito de autonomia está relacionado com/seguido de corresponsabilização. Apresenta-se, assim, uma perspectiva de redução de danos, que remete ao controle dos indivíduos, demarcando a autonomia com um sentido de responsabilização.

Não há divergências entre os documentos em relação à participação. Ressalte-se, no entanto, que no documento de 2006 nomeia-se somente como participação social e a gestão aparece um pouco mais. Remete-se à discussão do empoderamento, individual e comunitário, e também o empoderamento relacionado à discussão do controle social, que se estabelece pela relação com os direitos do consumidor, empoderamento este que remete a outra discussão, voltada para a responsabilização. Uma diferença importante para o documento de 2002 é que não há em 2006 a referência ao termo "emancipação".

O desafio de propor a intersetorialidade é tratado no documento de 2006 como atribuição do gestor federal do SUS. Assim, a intersetorialidade deve partir da saúde e remete-se o debate para dentro, incitando a articulação com os setores a partir do debate da saúde e das prioridades estabelecidas pelo nível federal.

As situações de vulnerabilidade, em especial de grupos específicos, com situações de risco, que são tratados em relação ao risco de adoecer e risco para doenças e agravos não transmissíveis aparece como preocupação central do documento. Há menor ênfase nas evidências, mencionando que a maioria das evidências já estabelecidas refere-se à vertente comportamental, produzidas pela epidemiologia. Com isso, estabelece que os estudos devem ser capazes de produzir evidências para comprovar a efetividade das ações.

Ambos os documentos enfatizam a importância da avaliação, sendo que o de 2006 estabelece os mecanismos para este fim, colocando sempre como uma das etapas dos processos. O de 2002 refere-se ao conteúdo e desenho avaliativo que deve condizer com a complexidade da promoção.

Numa análise de cada vertente de discussão, pode-se depreender que o documento de 2002 apresenta diferentes eixos de discussão e os aprofunda na discussão do campo, mas não assume propostas específicas para implementação da política; já o documento de 2006 traça outro caminho, perde na profundidade do debate e apresenta muitas proposições para o desenvolvimento da política. 


\section{A Promoção da Saúde na visão dos atores}

As entrevistas trazem de forma mais específica os sentidos em disputa na construção da política (quadro 2). A leitura das falas dos atores traz a percepção de como foi o processo para análise dos sentidos e a discussão que eles estavam propondo a partir do que vimos nos documentos, nos permitindo o estabelecimento de categorias de análise para compreensão do processo. Desta forma, a partir das entrevistas, localizamos no debate em torno dos sentidos da promoção a discussão travada entre o que identificamos como grupo da Promoção da Saúde e representantes da Reforma Sanitária, pois esta discussão, a nosso ver, constituiu uma diferença importante no debate da promoção no Brasil em relação a outros países e definiu diretrizes para a política também diferenciadas.

O grupo da Promoção trazia para o debate a importância de discutir a reconfiguração do modelo e creditava na proposta a perspectiva de mudança do sistema, tornando-se o marco para a mudança conceitual e prática da saúde pública. Para os representantes da reforma, esse entendimento da promoção como uma renovação do marco conceitual da saúde anulava a trajetória de discussão da reforma sanitária brasileira e não fazia justiça com as conquistas obtidas no âmbito político e institucional. Assim, estes representantes da reforma resgatavam a trajetória brasileira de crítica ao modelo de atenção e apontavam para o movimento que era anterior a Carta de Ottawa, reforçando a singularidade e radicalidade do projeto reformista.

Não havia divergências profundas de valores e propostas para o sistema de saúde entre estes grupos, mas havia uma disputa de reconhecimento histórico da trajetória política brasileira de construção do nosso modelo, numa oposição à ideia de que a promoção era "a salvadora da pátria" e de uma recusa à colonização de ideias pelos organismos internacionais.

O debate "promoção - reforma sanitária" também suscitou a explicitação da crítica a algumas nuances da promoção, como a crítica às propostas mais "Lalonde" ou mais "Ottawa". "Ser mais Lalonde" significava apostar numa promoção focada na difusão de hábitos saudáveis e com foco nos estilos de vida. "Ser mais Ottawa" era uma aposta numa promoção orientada pela perspectiva dos determinantes sociais e condições de vida. Nesta discussão, apresentaramse de forma mais aguda os diferentes sentidos de promoção dentro do próprio campo, presentes também no debate canadense, mas com outra ênfase. 
454

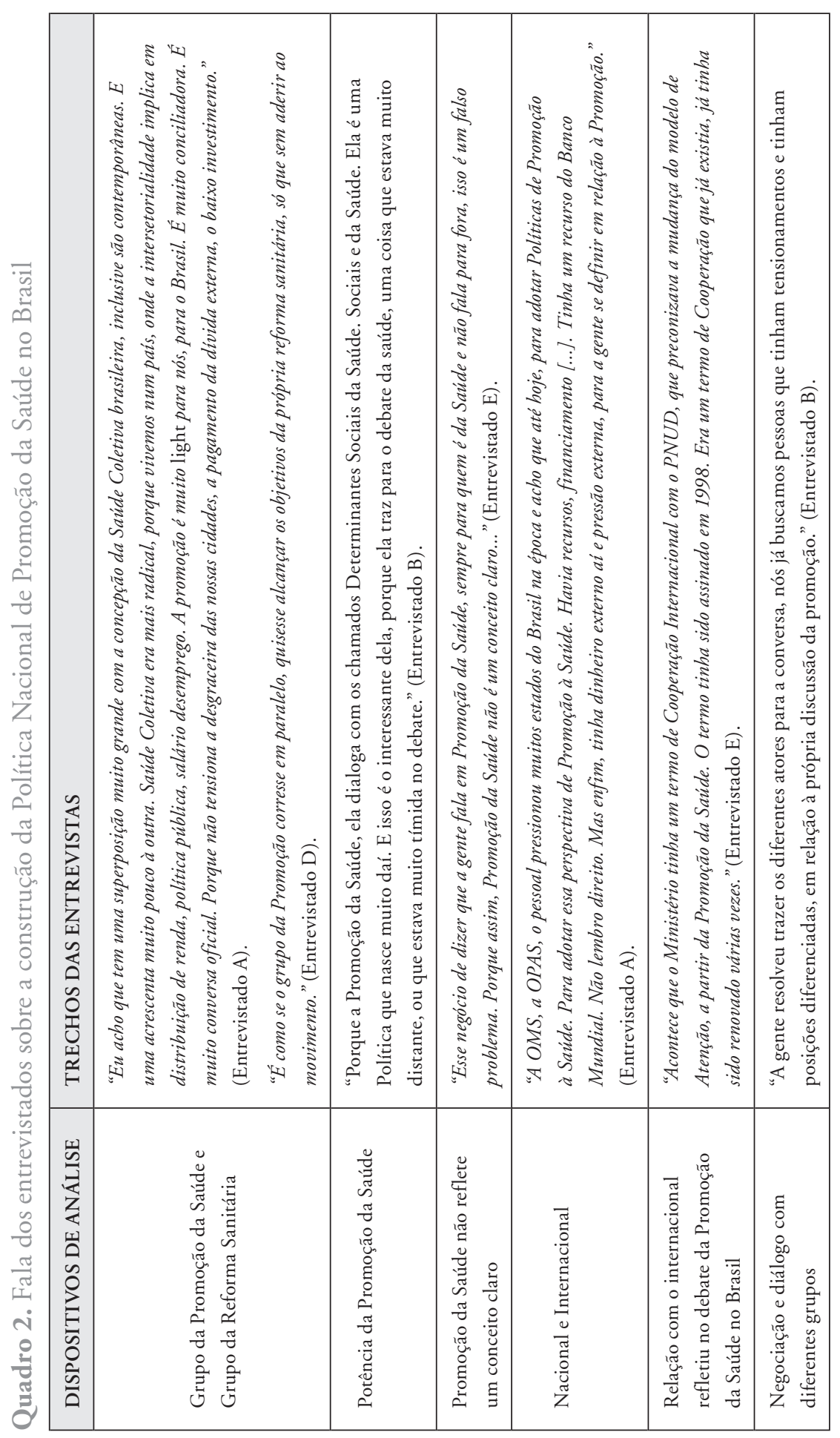




\begin{tabular}{|c|c|c|c|c|c|c|c|c|}
\hline 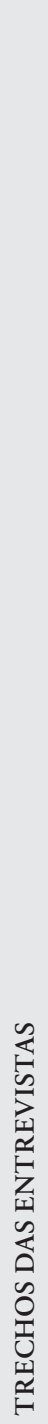 & 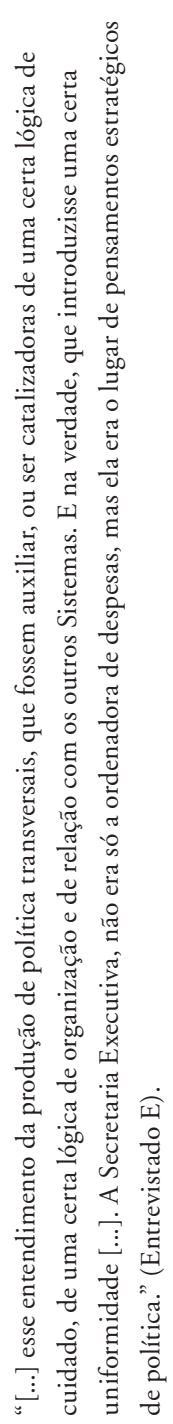 & 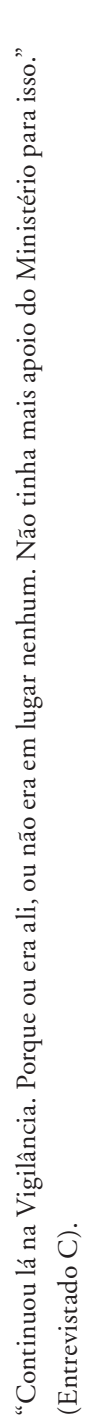 & 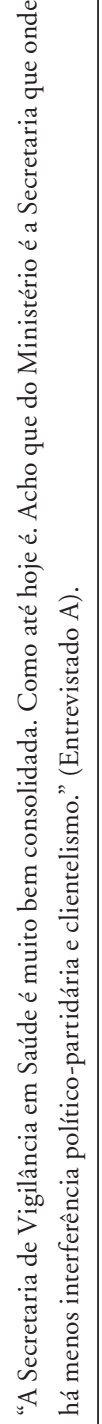 & 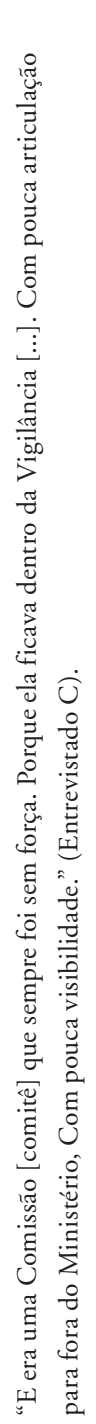 & 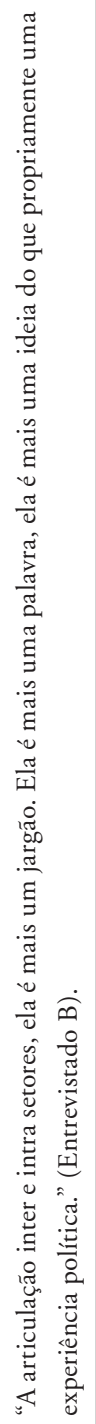 & 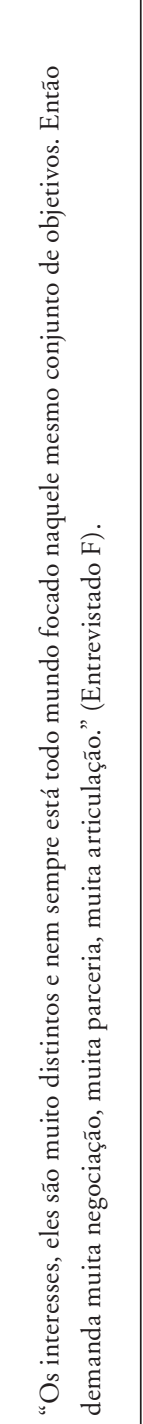 & 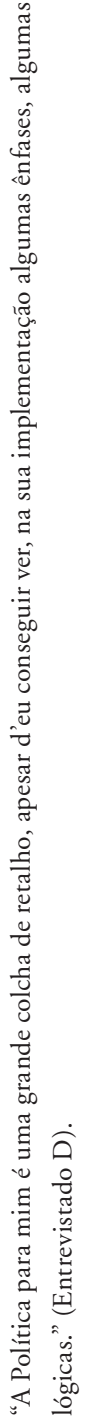 & 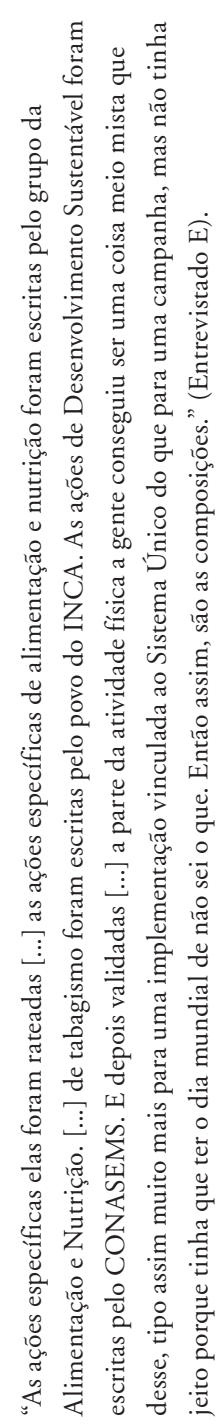 \\
\hline 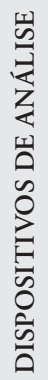 & 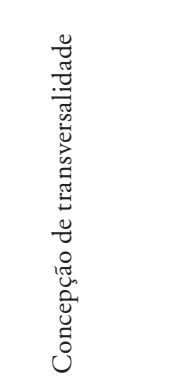 & 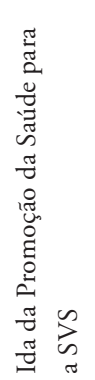 & 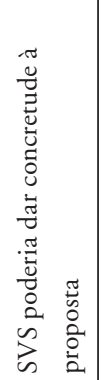 & 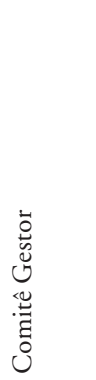 & 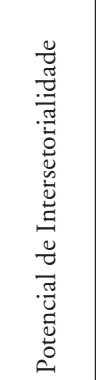 & 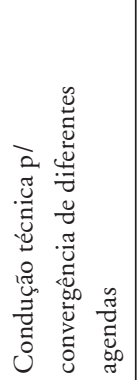 & & 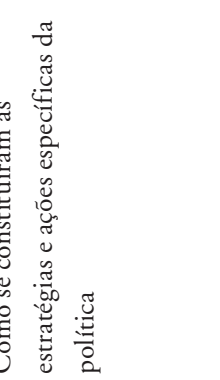 \\
\hline
\end{tabular}




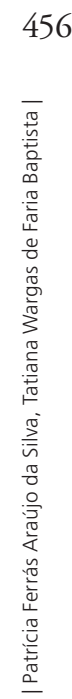

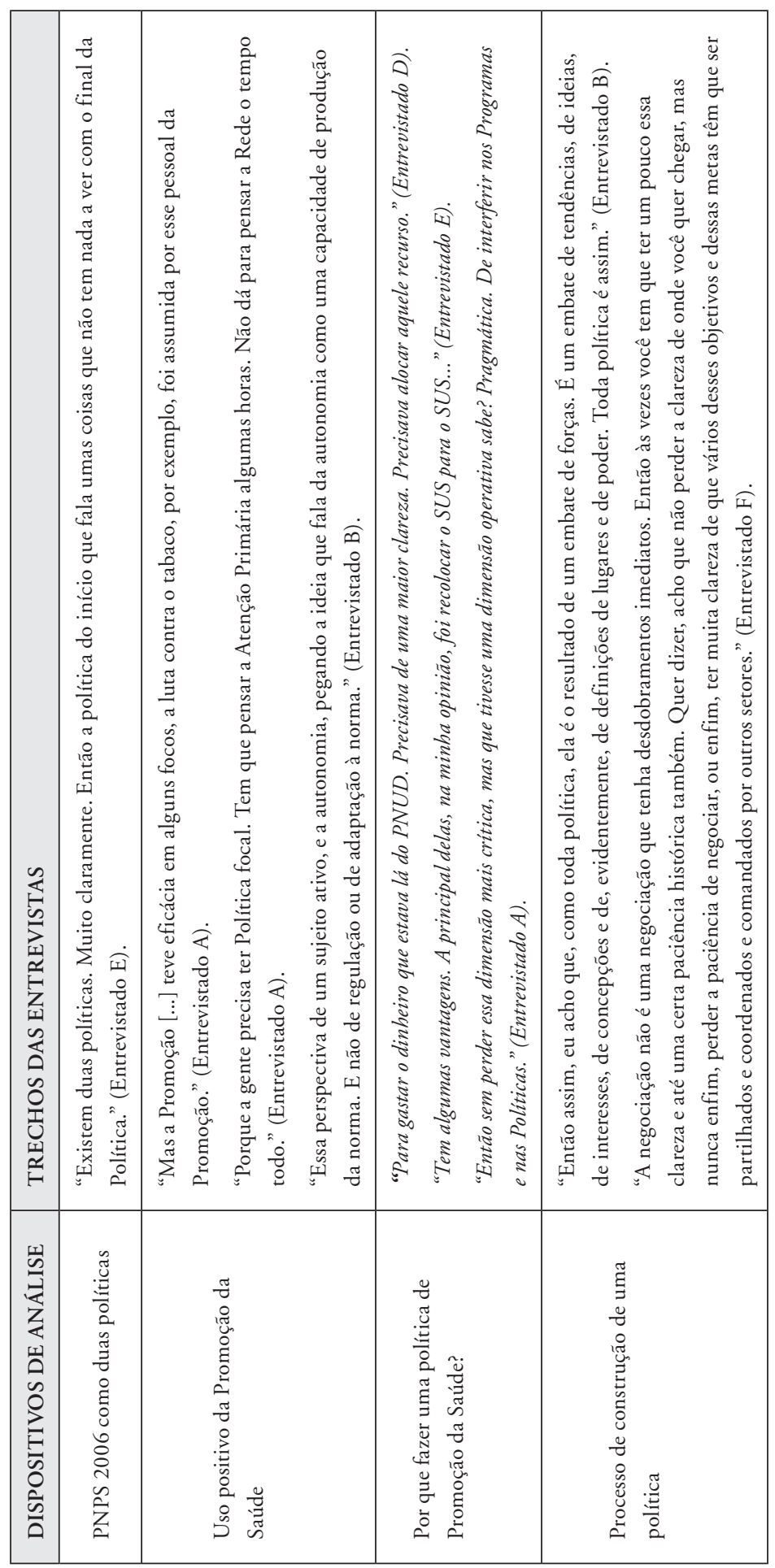


Essas divergências em torno do conceito de promoção geraram também um debate sobre o que seria sua potência enquanto política, seu maior ou menor alcance, revelando-se na fala dos entrevistados como uma promoção "mais ampla" ou "mais restrita". Neste debate, parece instalar-se a disputa de posições sobre o melhor rumo para a promoção que se apresenta na forma de oposiçóes como macro-micro, maior-menor, amplo-reduzido, grande-pequeno, Ottawa-Lalonde. A polarização trouxe tensóes importantes na definição do projeto político, não possibilitando muitas vezes a percepção da potência de mudança presente nos dois âmbitos.

Essa tensão representou uma armadilha para a promoção, uma vez que as ações mais específicas, como as relacionadas a hábitos saudáveis, foram rotuladas como menos importantes, e as ações mais gerais, mais ligadas à "política", como debates intersetoriais, foram valorizadas, posicionando o debate num nível de abstração elevado, incapaz de dialogar com experiências reais, propostas factíveis, protegidos pelo falso conforto do discurso, do não implementado.

Mas há também nas falas de alguns entrevistados o reconhecimento da existência de uma potência da promoção, indicando que ela não deveria ser pensada nem macro nem micro, não havendo dicotomia, porque a promoção deveria transitar por esses espaços, não devendo ficar apenas no discurso, na ação fluida ou remetida a outros setores, porque isso desobrigaria o gestor e profissional de sua responsabilidade, desresponsabilizaria a saúde da atenção.

$\mathrm{O}$ processo de construção da política nos remeteu ainda à tensão entre o nacional e internacional, uma vez que o movimento internacional estabeleceu prioridades e formas de conduzir propostas de promoção, estimulando a entrada da promoção na agenda dos governos. Havia uma conversa para fora, com o movimento internacional, que envolvia parcerias e também financiamento e repasse de recursos e, consequentemente, influenciava a agenda brasileira de promoção. O diálogo com os organismos internacionais se estabeleceu através de termos de cooperação e parcerias que viabilizavam a execução de muitas ações, em função, dentre outros fatores, da impossibilidade de contratação direta pelo Ministério da Saúde. Esta relação com o internacional refletiu no debate da promoção no Brasil.

O processo para a conformação de uma política de promoção envolveu negociação e diálogo com diferentes grupos em torno da construção de uma 
proposta que atendesse a demandas de diferentes segmentos. Era o desafio de formalização de uma política nacional. A construção da política foi se desenhando com diferentes atores em torno de uma estratégia de promoção que fosse implementável. Os atores da rede nacional envolvidos na construção da política inseriam-se em diferentes lócus de discussão, seja na gestão, na academia ou enquanto consultores com expertise na área.

No âmbito da Secretaria Executiva (SE), onde a área de promoção ficou vinculada no período de 2003 a 2004, buscou-se a construção de uma política de promoção partindo de uma concepção de transversalidade. No entanto, o processo de construção foi atravessado por mudanças importantes de gestão e de governo. A ida da área da promoção para a Secretaria de Vigilância em Saúde (SVS), no final de 2004, representou mudanças importantes no debate da política, a principal delas a redefinição do enfoque das propostas e açōes específicas da Política Nacional, com ênfase no processo de regulação, mais voltado a um sentido estrito de vigilância.

A ida para a vigilância suscitou divergências em torno do sentido de promoção versus controle, muito embora também se tenha percebido alguns ganhos, reconhecendo que a SVS poderia dar concretude à proposta. As apostas em torno da política enquanto estava na SE giravam em torno da construção de uma política estratégica, que pudesse ser transversal aos demais setores do Ministério da Saúde. Com a ida para a SVS, para que se mantivesse a busca da transversalidade e o diálogo com outros atores, foi instituído o Comitê Gestor, que tinha como principal desafio estabelecer ou mesmo construir um diálogo com as diferentes áreas do Ministério. A opção por incluir as diferentes secretarias e não abrir para fora do ministério, do setor Saúde, ao mesmo tempo em que representava a fragilidade pela sua alocação, era também uma aposta no que seria viável, na preocupação com a capacidade de gestão. Percebe-se que a proposta do Comitê era essencialmente intrasetorial, já que a articulação dentro do setor saúde não se estabelecia com facilidade, em função da divergência de agendas e prioridades de cada pasta. Muito embora, em função da proposta de intersetorialidade, se esperasse que o Comitê tivesse a participação de outros setores em sua composição. Por este motivo, a discussão ficou muito restrita ao setor saúde e, assim, o potencial de intersetorialidade revelou-se um aspecto frágil na elaboração da política. 
Desta forma, a construção da política exigiu uma condução técnica para a convergência de diferentes agendas consideradas prioritárias. E, para esta definição, alguns aspectos foram fundamentais, como a entrada de projetos que já tinham alguma proposta em andamento, que por consequência tinham maior possibilidade de entrada, o que privilegiou o olhar para determinadas questôes. Esse processo complexo nos permite compreender como se constituíram as estratégias e açôes específicas da politica, que representava diferentes interesses em torno do fazer saúde.

E ainda que no texto final, muitas ações sejam restritivas do ponto de vista da regulação dos sujeitos, podem também expressar um uso positivo da promoção na articulação de mudança de práticas nas áreas implicadas, como tabaco, atividade física.

Para os entrevistados, a potência da promoção se apresenta na articulação com a Atenção Primária e rede, na articulação de práticas em projetos nos territórios e comunidades, numa aposta de que a PNPS seria geradora de autonomia em oposição à regulação.

\section{Discussão}

Se reconhecemos que a promoção pode ser imbuída de diferente sentidos, é fundamental que na análise do processo de formulação da PNPS possamos identificar os sentidos em disputa, para facilitar o entendimento das diferentes apostas contidas no documento, bem como da direção que se quer alcançar com o enunciado desta política, em especial refletirmos por que fizemos esta política e o que pretendemos alcançar com ela. Desta forma, alguns tensionamentos merecem destaque e podem ser entendidos como dilemas que o debate da promoção suscita.

Um primeiro dilema apresentou-se no debate propriamente dito em torno do modelo de promoção, que decorre desta polarização historicamente construída e revela o componente político e ideológico das práticas, enunciados, políticas e programas. O debate basicamente se estrutura em torno de dois grandes blocos em disputa: a perspectiva regulatória versus perspectiva emancipatória (HEIDMANN et al., 2006; BUSS, 2000). A perspectiva regulatória, que se apresenta focada nos hábitos individuais, desvinculada dos determinantes sociais da saúde, culpabilizadora, vincula-se à Lalonde (Promoção da Saúde Moderna) com propostas baseadas nos estilos de vida (STOTZ; ARAÚJO, 2004). 
Para alguns autores, esse enfoque despolitiza o debate, negligencia o contexto político, econômico e social, responsabiliza determinados grupos sociais por seus problemas de saúde (HEIDMANN et al, 2006; STOTZ; ARAÚJO, 2004; MARCONDES, 2004). A ideia de controle dos indivíduos, que favorece a intervenção do Estado na indução de adoção de hábitos saudáveis é potencializada pela vigilância.

Já a perspectiva emancipatória está voltada aos determinantes sociais da saúde, como estratégia para o enfrentamento das questōes da saúde, entendendo que ultrapassa os limites deste setor, sendo necessário o desenvolvimento de ações intersetoriais capazes de ofertar alternativas que reconheçam a saúde enquanto conceito ampliado, inerente à complexidade de nossa organização social. Esta proposta vincula-se à Ottawa (Nova Promoção da Saúde), sendo centrada nos fatores sociais e ambientais.

A captura estrita por uma ou outra perspectiva se apresenta em outras tensões do campo, levando-nos a um segundo dilema que se refere à apropriação desta polarização, desdobrando-se na discussão entre o amplo e o restrito. Essa dicotomia produziu uma falsa diferenciação onde as propostas voltadas para o coletivo seriam consideradas amplas, pensadas a partir de uma "esfera macro", comprometida com um projeto emancipatório, fazendo com que propostas voltadas para o individual tivessem um caráter menor, restrito, fragmentado, reforçando uma perspectiva de controle, regulatória.

Essa tensão despolitiza o debate da promoção, que deve ser compreendido pela sua capacidade de representar possibilidades de ação com diferentes dimensões, que não pretendem se deter na esfera individual, mas que também não abrem mão dela. Este é um dos aspectos centrais da PNPS, que ao apresentar propostas de ações específicas de implementação incorrem no risco da captura por açôes restritivas, que favoreçam a culpabilização individual. Isto porque na medida em que estejam "prescritos" os comportamentos e hábitos saudáveis, aqueles que não aderem às propostas estariam assumindo o risco, nesse caso, do desenvolvimento das doenças crônicas não transmissíveis (DANT).

O processo que torna os indivíduos coparticipantes na busca por melhores condições de saúde, tanto pode culpabilizar e responsabilizar pela não saúde, quanto pode instrumentalizar para torná-los atores-chave. Estas perspectivas em disputa apresentam-se também no processo de construção da PNPS, que 
apesar de ser pensada como uma proposta de política transversal, que pressupõe a participação social e busca pela autonomia, ainda reforça práticas de caráter individual, focalizadas nas mudanças de hábitos, que se voltam muito mais para o controle do que para a emancipação dos indivíduos.

Este embate nos remete ao terceiro dilema, que se traduz no emprego do conceito de empowerment, que pode ser utilizado com diferentes sentidos, dividindo a opiniāo de autores no campo da promoção. Este conceito traduz boa parte dos conflitos relacionados à temática e admite interpretações diversas (CARVALHO; GASTALDO, 2008).

Se por um lado a noção de empowerment pode favorecer o protagonismo da população, numa mudança de paradigma que os torna coparticipantes e aumenta o controle dos indivíduos nos processos que envolvam sua saúde, mediante a participação efetiva na constituição de prioridades e no desenvolvimento das ações (BUSS, 2000), por outro pode legitimar um processo de responsabilização da população pela eventual falta de autocuidado, favorecendo a retirada ou diminuição do papel do Estado na saúde, deixando a cargo da sociedade civil o desenvolvimento de ações que viessem ao encontro de suas demandas, num processo de culpabilização das vítimas da iniquidade social (HEIDMANN et al., 2006; MARCONDES, 2004; CARVALHO, 2004). O risco é que a utilização do empowerment possa "facilmente converter-se em justificativas ideológicas para a privatização e a desregulamentação dos serviços de saúde" (CARVALHO, 2004, p. 1.093).

Nesse sentido, "o uso da noção de empowerment sem reflexôes críticas e análises políticas das relações de poder na sociedade dissemina visões vagas, românticas e homogêneas da comunidade" (FERREIRA; CASTIEL, 2009 p. 75), muito embora em outra perspectiva a categoria empowerment corporifique a razão de ser da Promoção da Saúde enquanto um processo que procura possibilitar que indivíduos e coletivos aumentem o controle sobre os determinantes da saúde para, desta maneira, terem uma melhor saúde (CARVALHO, 2004).

As tensões que nos levam a refletir acerca dos "dilemas promocionistas" nos remetem ao dilema preventivista de Arouca (2003), que fundamentou na dicotomia indivíduo versus coletivo a crítica à Medicina Preventivista, que culpabilizava os indivíduos e representava um afastamento do real, não buscava compreender a "causa das causas" e focalizava apenas uma dimensão do cuidado 
à saúde em detrimento de uma discussão mais abrangente sobre os determinantes sociais. Arouca foi um dos precursores do Movimento de Reforma Sanitária no Brasil, com a preocupação de que se construísse um modelo de atenção a partir da discussão da causa das causas, que não se restringisse a nenhum dos níveis de atenção, mas que buscasse a saúde de maneira integral.

Assim, os "reformistas" buscavam a garantia da saúde como um direito de cidadania, que considerasse os aspectos sociais que interferiam diretamente nas condições de vida e saúde da população. Esse movimento, que ocorreu em paralelo com o movimento internacional de promoção da saúde, também suscitou um dilema na disputa entre "promocionistas" e "reformistas", que se deu numa crítica dos últimos à desconsideração da trajetória de construção da reforma e de debate em torno do conceito ampliado de saúde, numa busca de diálogo com o debate internacional. Havia o questionamento dos reformistas em atribuir ao movimento internacional algo que já fazia parte das bandeiras de luta da reforma sanitária no Brasil. Além disso, temia-se que com o discurso da promoção houvesse o retorno ao dilema preventivista, agora representado pela dicotomia que mantém separada a promoção e a clínica, o "dilema promocionista” (ONOCKO, 2006), como se fosse possível em nome da promoção deixar de prover os meios para a atenção e recuperação, como se uma estratégia pudesse substituir a outra.

Mas, por trás desse debate, o principal conflito que pretendemos desvelar é o dilema que se configura na relação da promoção com o campo da saúde. Percebese um encapsulamento da discussão, que se volta para dentro, que se pretende intersetorial, mas não estabelece o diálogo necessário com outros setores, que concentra no setor saúde a responsabilidade de dar conta sozinho de questóes que estão muito além de sua governança. O enunciado da PNPS não condiz com seu alcance real, uma vez que as propostas e atores, a exemplo do comitê gestor, pertencem ao setor saúde, com poucas possibilidades de transversalidade.

Não se pode pensar em promoção da saúde sem considerar os determinantes sociais, o conceito ampliado de saúde, a conversa para fora do setor saúde, bem como a trajetória brasileira de luta pelo direito à saúde, uma vez que as ações que não se pautem por esses referenciais contribuem para o aumento das desigualdades e responsabilização individual, retornando ao que já se discutia há anos com Arouca, que alertava para o perigo da despolitização do debate, com discursos que não rompem com práticas conservadoras e modelos de atenção à saúde que desconsideram o contexto social. ${ }^{1}$ 


\section{Referências}

AROUCA, A.S.S. O dilema preventivista: contribuição para a compreensão e crítica da medicina preventiva. Rio de Janeiro: Fiocruz, 2003.

BAPTISTA, T.W.F.; MATTOS, R.A. Sobre Política (ou o que achamos pertinente refletir para analisar políticas). In: MATTOS, R.A.; BAPTISTA, T.W.F. Caminhos para análise das políticas de saúde [versão online]. p. 52-91. Rio de Janeiro: IMS/UERJ-ENSP/FIOCRUZEPSJV/FIOCRUZ; 2011. Disponível em www.ims.uerj.br/ccaps Acesso em: 09 fev. 2012.

BRASIL. Ministério da Saúde. Política Nacional de Promoção da Saúde. Brasília: MS, 2006. Ministério da Saúde. Política Nacional de Promoção da Saúde (Documento para discussão). Brasília: MS, 2002.

BUSS, P.M.; CARVALHO, A.I. Desenvolvimento da promoção da saúde no Brasil nos últimos vinte anos (1988-2008). Rev C S Col., Rio de Janeiro, v. 14, n. 6, p. 2.305-2.316, 2009. BUSS, P.M. Promoção da saúde e qualidade de vida. Rev C S Col., Rio de Janeiro, v. 5, n. 1, p. 163-1772000.

CARVALHO, A.I. Princípios e prática da promoção da saúde no Brasil. Cad Saúde Pública, Rio de Janeiro, v .24, n. 1, p. 4-5, 2008.

CARAVALHO, S.R.; GASTALDO, D. Promoção à saúde e empoderamento: uma reflexão a partir das perspectivas crítico-social pós-estruturalista. Rev C S Col., Rio de Janeiro, p. 2.029-2.040, 2008.

CARAVALHO, S.R. Os múltiplos sentidos da categoria "empowerment" no projeto de Promoção à Saúde. Cad Saúde Pública, Rio de Janeiro, v. 20, p. 1088-95, 2004.

FERREIRA, M.S. et al. Promoção da Saúde: entre o conservadorismo e a mudança. Disponível em: http://www.cbce.org.br/cd/resumos/023.pdf Acesso em: 10 out. 2011.

FERREIRA, M.S.; CASTIEL, L.D. Which empowerment, which Health Promotion? Conceptual convergences and divergences in preventive health practices. Cad Saúde Pública, Rio de Janeiro, v. 25, n. 1, p. 68-76, 2009.

GIDDENS, A. A constituição da sociedade. São Paulo: Martins Fontes, 2003.

HEIDMANN, I.T. et al. Promoção à saúde: trajetória histórica de suas concepções. Texto Contexto Enfermagem, Florianópolis, v. 15, n. 2, p. 352-8, 2006.

MARCONDES, W.B. A convergência de referências na promoção da saúde. Saúde e Sociedade, São Paulo, v. 13, n. 1, p. 5-13, 2004.

MATTOS, R.A. Ciência, Metodologia e Trabalho Científico (ou tentando escapar dos horrores metodológicos). In: MATTOS, R.A.; BAPTISTA, T.W.F. Caminhos para análise das políticas de saúde [versão online], p. 20-51. Rio de Janeiro: IMS/UERJ-ENSP/ FIOCRUZ-EPSJV/FIOCRUZ, 2011. Disponível em www.ims.uerj.br/ccaps. Acesso em: 09 fev 2012. 
ONOCKO-CAMPOS, R. A promoção à Saúde e a clínica: O dilema "promocionista”. In: CASTRO, A.; MALO, M. (Org.). SUS: ressignificando a promoção da saúde. São Paulo: Hucitec, 2006.

SPINK, M.J. (Org.). Práticas discursivas e produção de sentidos no cotidiano. São Paulo: Cortez, 2004.

STOTZ, E.N.; ARAÚJO, J.W.G. Promoção da saúde e cultura política: a reconstrução do consenso. Saude e Sociedade, São Paulo, v. 13, n. 2, p. 5-19, 2004.

\section{Nota}

${ }^{1}$ P.F. da Silva e T.W. de F. Baptista trabalharam conjuntamente na elaboração do artigo, desde a análise e discussão dos dados até a redação do manuscrito. 


\section{Abstract}

The senses and disputes in the construction of the National Health Promotion Policy

This study aimed to examine the definition of the National Health Promotion Policy in 2006 in Brazil, trying to explain the meanings and disputes in the formulation and its implications for the field of healthcare process. For this purpose, literature review, analysis of documents and interviews with participants in the discussion of health promotion network in Brazil were made. We start from a constructionist view of science, including the policy as a dynamic process that is different from the factors that influence the choices and positions of actors and groups. We identify some tensions in the process can be understood as dilemmas that the debate raises. A first dilemma presented itself in the debate around the promotion model, which stems from the polarization historically constructed between the regulatory perspective and emancipatory perspective. A second dilemma concerns the ownership of this discussion unfolding in bias between the broad and narrow, where the proposals impacting the collective are seen as committed to an emancipatory project and proposals geared to the individual are understood from the perspective of control. The third dilemma has resulted in the employment of the concept of empowerment without a thorough discussion of its effect on the construction process of this policy in our framework.

> Key words: health promotion; health policy; policymaking. 